\title{
A integralidade como eixo da formação em proposta interdisciplinar: estágios de Nutrição e Psicologia no campo da Saúde Coletiva
}

\author{
The comprehensive care as the axis of interdisciplinary \\ training: Nutrition and Psychology undergraduate \\ in the field of Public Health
}

Maria Angélica Tavares de MEDEIROS ${ }^{1}$

Florianita Coelho BRAGA-CAMPOS²

Maria Inês Badaró MOREIRA'

RE S U M O

Trata-se de relato de experiência de estágio interdisciplinar em Nutrição Social e em Psicologia da Universidade Federal de São Paulo campus Baixada Santista, com foco na integralidade da atenção. O trabalho ocorreu entre 2010 e 2012, na Atenção Básica de Saúde do Sistema Único de Saúde no território Centro/Morro do município de Santos, São Paulo. Utilizaram-se registros de campo contendo memórias de supervisões e de reuniões entre professores e equipe de saúde. Construíram-se narrativas e projetos terapêuticos singulares. Em supervisão conjunta de professores de Nutrição e Psicologia, debateram-se situações destacadas pelos estudantes e planos de trabalho construídos para cada ciclo de formação. Isto fundamentou práticas interdisciplinares, reflexões e ações consoantes ao Sistema Único de Saúde, realizadas pelos estagiários. Os resultados corroboram a importância do trabalho interdisciplinar para a promoção da integralidade, constituindo formas de escuta e atenção diferenciadas aos usuários, em estreita relação com os serviços.

Termos de indexação: Comunicação interdisciplinar. Estágios. Integralidade em saúde. Sistema Único de Saúde.

A B S T R A C T

This paper aimed to analyze the experience in interdisciplinary training for Nutrition and Psychology undergraduate courses at the Baixada Santista campus of Universidade Federal de São Paulo, focusing on

1 Universidade Federal de São Paulo, Instituto Saúde e Sociedade, Departamento de Políticas Públicas e Saúde Coletiva. Campus Baixada Santista, R. Silva Jardim, 136, Edifício Central, Vila Mathias, 11015-020, Santos, SP, Brasil. Correspondência para/

Correspondence to: MAT MEDEIROS.E-mails: <angelica.medeiros@unifesp.br>; <angelicamedeiros@gmail.com>.

${ }^{2}$ Universidade Federal de São Paulo, Instituto Saúde e Sociedade, Departamento de Saúde, Clínica e Instituições. Santos, SP, Brasil. 
comprehensive care. It took place between 2010 e 2012, in the Primary Care Health of Unified Health System of Santos municipality, São Paulo, Brazil, in the the territory of Monte Serrat Hill. We used field records from memories of supervisions and meetings between teachers and health team, according to qualitative research. Narratives have been constructed and Singular Therapeutic Projects. In joint-supervision by professors of Nutrition and Psychology courses, we debated situations highlighted by students and constructed work plans for each training cycle. Through interdisciplinary practices reflections and actions to SUS consonants were realized. Our results corroborate the importance of interdisciplinar work towards comprehensive care, promoting ways of listenning which leads to special health care in close relation to the services.

Indexing terms: Interdisciplinary communication. Internships. Integrality in health. Unified Health System.

\section{N T R O D U ÇÃ O}

A reflexão sobre os desafios que perpassam a formação em saúde compõe a agenda atual de pesquisadores e profissionais no Brasil ${ }^{1-6}$. Historicamente a formação nesta área se nucleou nas ciências biológicas e no paradigma flexineriano de assistência médica, centrado no procedimento estritamente curativo e hospitalar?

No âmbito nacional, o ensino voltado ao aprendizado de técnicas especializadas e fragmentado em relação ao universo que o contorna, passou a ser questionado nos anos 1980, no bojo da crise econômica e social decorrente da modelo econômico excludente do Governo Militar ${ }^{6,8}$. Rearranjos para as políticas públicas se impuseram, destacando-se a Reforma Sanitária que culminou com a criação do Sistema Único de Saúde (SUS), em 1988 e sua regulamentação em 1990, aproximando o Ministério da Saúde às questões pertinentes ao aprimoramento das graduações e forçando o ensino universitário a rever a formação profissional ${ }^{1,5,9}$. As demandas de reestruturação curricular dos cursos da saúde voltaram-se, então, a uma formação profissional comprometida com a efetivação dos princípios e das diretrizes do SUS, com destaque para a integralidade do cuidado, a interdisciplinaridade, o trabalho em equipe, assim como para a adoção de metodologias ativas de ensino-aprendizagem.

Nesse sentido se inserem novos desenhos para os cursos de Nutrição e as Diretrizes Curriculares para estes cursos abrigaram recomendações de ampliação das capacidades dos profissionais nutricionistas. Isto favoreceu a proposição de Projetos Político-Pedagógicos mais afinados com as necessidades de saúde e nutrição da população brasileira ${ }^{6,10}$. A necessidade de ajustes na graduação de nutricionistas em busca da formação com perfil generalista foi objeto de preocupação das várias subáreas da Nutrição. No âmbito da Nutrição Social destacam-se as contribuições para a construção do campo da Alimentação e Nutrição em Saúde Coletiva, que passaram a referenciar a formação na graduação, assim como a produção de conhecimento comprometida com a formulação de políticas voltadas aos dilemas da realidade brasileira nesse terreno ${ }^{2,11-13}$.

Assim como demais profissionais convocados ao trabalho no SUS, psicólogos com formação direcionada ao exercício privatista e autônomo inseriram-se nos equipamentos de saúde com práticas descontextualizadas e pouco comprometidas com a vida concreta dos sujeitos alvo. Ainda na década de 1990, pesquisas anunciavam essas práticas equivocadas no contexto do SUS apontando a necessidade de mudanças dos currículos de Psicologia. Esta situação evidenciava a dicotomia entre a formação, eminentemente teórica e voltada ao trabalho clínico privado, e a realidade que o profissional do SUS encontrava nos serviços em que se inseria ${ }^{14}$. Desse modo, sobressaiu a necessidade de alteração da formação do psicólogo visando a um trabalho nos serviços de saúde que tomasse o homem e seu contexto de vida como alvo de ação. As novas Diretrizes Curriculares para os cursos de Psicologia entraram em vigor em 2004, confirmando as prioridades para uma formação generalista comprometida com as transformações sociais, contrapondo-se ao modo especialista oriundo da formação tradicional ${ }^{15}$. 
Novos marcos para a capacitação foram estabelecidos e, desde 2001, as Diretrizes Curriculares para a formação de profissionais da área de saúde propugnam a incorporação de conteúdos concernentes ao SUS. O marco legal do SUS motivou a reestruturação curricular ${ }^{5,16}$, assim como a inserção de novos protagonistas no campo da saúde provocou o redesenho da formação, condizente com os princípios e as diretrizes do SUS, na perspectiva da integralidade e interdisciplinaridade. Distintos cursos de graduação na área de saúde foram convocados a viabilizar propostas centradas em estratégias inovadoras de ensino/ aprendizagem e em práticas interdisciplinares 5,17.

Dentre diversas iniciativas de responder à necessidade de redirecionamento dos projetos de formação para o trabalho em saúde, a Universidade Federal de São Paulo (Unifesp), em seu campus da Baixada Santista (BS), priorizou um Projeto Politico-Pedagógico vocacionado à formação para o SUS, comprometendo-se com a educação pautada no trabalho interdisciplinar dos cursos ofertados.

O objetivo deste artigo é relatar e analisar experiência de estágio interdisciplinar em Nutrição e em Psicologia na Atenção Básica e de Média Complexidade do SUS de Santos. O foco foi a delimitação de um território de atuação das equipes de docentes e estagiários da Unifesp/BS, com vistas a produzir uma rede de cuidado à saúde dos indivíduos e de suas famílias, contribuindo para a integralidade da atenção.

\section{M É T O D O S}

Trata-se de relato de experiência sobre a construção de estágios curriculares de Nutrição Social e de Psicologia na Atenção Básica e de Saúde Mental, que se encontravam em um mesmo território do SUS de Santos (SP), Brasil, no período de 2010 a 2012.

Para a elaboração deste relato foram utilizados como fontes de dados os Diários de Campo dos estudantes, no qual se registraram: memórias das reuniões de planejamento conjunto dos está- gios; memórias das supervisões semanais integradas de estágio e das reuniões entre docentes e equipes para acompanhar e analisar a implantação desta experiência e os relatórios finais de estágio. Depoimentos informais de integrantes das equipes e dos estudantes foram igualmente utilizados.

A análise desses documentos seguiu as premissas dos estudos qualitativos, em que diferentes registros foram examinados e os Diários de Campo se referenciaram na pesquisa etnográfica. A partir de leitura flutuante, se iniciaram as reflexões sobre o conteúdo do material. $\mathrm{Na}$ sequência, realizou-se uma leitura cuidadosa das fontes, com vistas ao resgate fiel de informações que contribuíssem para a apreensão da experiência vivida. Desse modo, as docentes supervisoras envolvidas aprofundaram a compreensão dos textos produzidos, como também a análise das percepções e significados do processo ocorrido, resultando na produção deste relato de experiência ${ }^{18-20}$.

A abordagem narrativa como técnica de pesquisa qualitativa foi adotada tanto nas orientações docentes para construção dos Diários de Campo pelos estagiários, quanto como ferramenta para a aproximação e a produção de vínculos com os usuários dos serviços nos quais esses estágios interdisciplinares tiveram lugar ${ }^{19,21-24}$.

\section{Cenário de práticas}

A escolha do cenário de práticas foi dada por diligência das equipes dos serviços, quando se firmou parceria entre a Unifesp/BS e a Secretaria Municipal de Saúde de Santos, em 2009. Tais solicitações, pactuadas segundo critérios de vulnerabilidade social, conduziram à eleição da Região Centro-Morro para atuação da Universidade, em ações de ensino, pesquisa e extensão. Há outros campos de estágios interdisciplinares na Unifesp/BS. O Estágio de Nutrição Social, por exemplo, ocorre em cinco Unidades Básicas de Saúde (UBS) e em três Unidades de Saúde da Família (USF), distribuídas em três Regiões de 
saúde de Santos: Morros, Noroeste e Orla. No escopo deste estudo descreve-se e analisa-se o caso do estágio de Nutrição Social e Psicologia na Atenção Básica no Território Centro-Morro.

Definiu-se uma Unidade de Saúde da Família, a USF Monte Serrat e, em torno dela, o Núcleo de Atenção Psicossocial de referência da Região (NAPS II), localizado em área circunvizinha do Centro Histórico. A partir deste território comum projetou-se a atuação no propósito de construir redes de cuidado aos usuários. Uma vez que - Monte Serrat é palco de outras práticas da Unifesp, as ações dos estágios também integraram diferentes atividades de ensino e extensão: Estágio de Nutrição Social - $7^{\circ}$ e $8^{\circ}$ semestres do curso de Nutrição; Estágio de Psicologia na Atenção Básica e Estágio de Saúde Mental no NAPS II, ambos correspondentes ao $9^{\circ}$ e $10^{\circ}$ semestres do curso de Psicologia. Atividades práticas do eixo comum Trabalho em Saúde, envolvendo seis cursos de graduação nos seguintes módulos: Prática clínica integrada: análise de demandas e necessidades em saúde ( $3^{\circ}$ semestre); e Clínica integrada: produção do cuidado (5 e $6^{\circ}$ semestres); Projeto de Extensão - Terreiro lá de casa: tem pequi, cuxá, pão de queijo, jambu... tem congada, boi bumbá, maracatu...25,26.

\section{Interdisciplinaridade trabalho em equipe, formação para o SUS: referenciais}

Desde 2006 a Universidade Federal de São Paulo responde à política universitária brasileira de ampliar vagas públicas, promovendo o deslocamento dos campi para municípios sede de grandes aglomerados urbanos. O campus instalado na Baixada Santista (Unifesp/BS) é responsável por seis cursos da área de Saúde: Psicologia, Nutrição, Fisioterapia, Terapia Ocupacional, Educação Física e Serviço Social.

O Projeto-Político-Pedagógico (PPP) da Unifesp/BS propõe importante contribuição para reorientar a formação de profissionais de saúde, ao priorizar uma educação sustentada na busca da integralidade e da interdisciplinaridade, articulando o ensino à extensão e à pesquisa, de modo a promover competências para o trabalho em equipe. Estas premissas revelam um compromisso com princípios e diretrizes do SUS, em resposta à demanda por profissionais sensíveis às necessidades de saúde de indivíduos e populações ${ }^{27,28}$.

Nesta proposta curricular os estudantes são inseridos em turmas mistas de seis cursos, em dinâmica que os aproxima da realidade social, ao fazer emergir os problemas do cotidiano dos usuários dos serviços públicos de saúde para as salas de aula ${ }^{28}$. Pressupõe-se o processo de produção do conhecimento em suas dimensões técnicas, conceituais e relacionais, buscando articular teoria e prática, a partir de estratégias metodológicas de problematização dos saberes.

Os cursos objetivam a formação de profissionais capacitados para atuar na promoção de saúde, rompendo com a tradicional estrutura curricular focada em disciplinas isoladas. Neste traçado, formulam suas diretrizes em torno de quatro eixos estruturantes, em que resguardam três eixos comuns e um específico para cada área, assim denominados: O ser humano em sua inserção social, O ser humano em sua dimensão biológica e o eixo Trabalho em saúde, e o eixo Aproximação à prática específica em saúde, respectivamente. Esses eixos abrigam módulos interdisciplinares para a integração dos conteúdos das diferentes disciplinas, adotando metodologias ativas de ensino-aprendizagem, que conduzam à autonomia do graduando na construção do conhecimento ${ }^{4,25,28-30}$.

O eixo Aproximação à prática específica em saúde contém os cursos de graduação, com seus módulos específicos distribuídos gradualmente nos anos de formação de cada profissão e intensificados nos últimos semestres. Além de trabalharem conteúdos fundamentais de cada profissão, elegem-se campos de estágios em que os alunos se inserem em serviços já reconhecidos, em atividades teórico-práticas dos eixos comuns. Neste sentido, também se configuram em amplo espaço para atividades coletivas, cujas ações em 
equipes são construídas a partir de intervenções de cada profissão. Os estágios buscam proporcionar ambiente de análise e produção de conhecimento na saúde, integrando ações e olhares sobre os sujeitos e seu entorno social.

Em síntese, o objeto deste relato foram os estágios de: Nutrição Social; Psicologia na Atenção Básica e Saúde Mental no NAPS II, que compõem o eixo Aproximação à prática específica em saúde da Unifesp/BS. A proposta de articular ações na ótica da integralidade baseou-se nos referenciais das políticas do SUS, a saber: a Política Nacional de Humanização, a Política Nacional de Alimentação e Nutrição (PNAN) e a Política Nacional de Saúde Mental ${ }^{11-33}$.

\section{RESULTADOSE DISCUSSÃO}

\section{Do comum ao específico, do específico ao comum: o exercício do trabalho em equipe}

O ponto de partida do trabalho foi a elaboração de Plano Integrado dos Estágios de Nutrição Social, de Psicologia na Atenção Básica e de Saúde Mental, em torno do qual foram concebidas ações comuns, abaixo sumarizadas:

1. Reconhecimento do território com seus fixos e fluxos, para apreensão dos modos de viver e das necessidades de saúde daqueles moradores e inserção na dinâmica do SUS santista. Neste mapeamento levaram-se em consideração questões econômicas, psicossociais, culturais e o contexto ampliado das práticas alimentares.

1.1. Sob responsabilidade dos estagiários de Nutrição ficaram a identificação do acesso a alimentos pelo comércio local (feiras, mercados, bares, lanchonetes/restaurantes dos estabelecimentos que lidam com alimentos) e de espaços para Educação Alimentar e Nutricional. Já os estudantes de Psicologia se organizaram para mapear os equipamentos sociais que lidassem com saúde, educação, esporte e lazer.
2. Identificação e observação da dinâmica dos serviços, buscando integrar-se às equipes e se inteirar das ações de Alimentação e Nutrição e de Saúde Mental no conjunto da gestão local. Para tanto, se fez necessário o acompanhamento da rotina das unidades de saúde, incluindo: fluxo do atendimento; gestão de cada setor (recepção, vacinação, atenção de enfermagem, farmacêutica, nutricional e das diversas clínicas, vigilância à saúde) e o conhecimento das fichas de registros e dos prontuários da população atendida.

3. Participação nas reuniões das equipes nas quais os estudantes verificavam demandas, como a elaboração de protocolos e de planos integrados de educação em saúde, conforme necessidades do serviço. Nesses momentos, os estagiários eram orientados a levar à discussão aqueles casos e situações mais complexos que haviam diagnosticado, para identificar caminhos de uma atenção qualificada e humanizada.

4. Organização pelos estudantes de uma semana padrão contemplando espaços comuns e específicos para a realização do estágio interdisciplinar.

5. Apresentação pelos estagiários de Planos de Ação com cronograma, segundo necessidades locais, prevendo a criação de mecanismos de avaliação permanente destes planos.

6. Identificação, junto às equipes de saúde, de casos a serem acompanhados nos domicílios.

7. Elaboração de Projetos Terapêuticos Singulares (PTS) para usuários, decididos em reuniões de equipe para o apoio Matricial, envolvendo acompanhamentos domiciliares, além de atividades comunitárias de cunho educativo demandadas.

8. Observação e inserção nas ações coletivas de educação em saúde (grupos educativos e terapêuticos) em desenvolvimento nos locais, conforme necessidades da população e das equipes. Destaca-se que compor as ações coletivas demandava planejamento integrado entre os estudantes de Nutrição e Psicologia, com o estudo de dinâmicas e técnicas de grupo focadas na 
interação, em detrimento de abordagens prescritivas, de tipo palestra.

9. Elaboração de Diário de Campo pelos estudantes, como forma não apenas de descrever o que foi feito, para disponibilizar este material às turmas seguintes, mas, sobretudo, de refletir sobre a prática, avaliar intercorrências e intervir sobre elas, e de auto-avaliação. Estes diários são objeto de avaliação processual dos docentes supervisores de estágio e são disponibilizados para estudos e reflexões futuras sobre estas práticas.

Tais atividades, previstas para as primeiras semanas, subsidiavam o planejamento de ações interdisciplinares entre esses estágios, além de se estenderem às demais iniciativas da Unifesp neste território, envolvendo os estágios de Educação Física e Fisioterapia e o módulo teórico-prático Clínica Integrada: produção do cuidado $\left(5^{\circ}\right.$ e $6^{\circ}$ semestres envolvendo alunos dos seis cursos de graduação).

A finalização dos estágios abarcava: o fechamento das visitas domiciliares e dos PTS com usuários e equipes, assim como das ações coletivas; dos casos escolhidos para aconselhamento nutricional e das ações interdisciplinares com os demais estágios; e a apresentação dos resultados às equipes dos serviços, em reuniões nos respectivos locais e em seminários realizados na universidade.

\section{O reconhecimento do território}

O reconhecimento do território e de seus equipamentos sociais foi a base para apreender a lógica da rede do SUS Santista, permitindo que os estudantes de Nutrição e de Psicologia construíssem percursos em que fixos e fluxos despontavam para o desenho de um mapa vivo da região. Assumiu-se a concepção territorial de Milton Santos, segundo a qual o espaço urbano configura um conjunto de relações sociais expressas por processos e funções, que se põem em suas contradições e desigualdades ${ }^{34}$.
Neste sentido, as cidades se distinguem umas das outras por seus fixos e fluxos, os quais, quando alterados, modificam toda a dinâmica das mesmas. Segundo o autor, os fixos podem ser econômicos, culturais, educacionais, sociais etc., sendo representados por pontos delimitados em um dado território. Em tal território, por sua vez, se movimentam os fluxos humanos, gerando novos serviços e possibilitando a visualização de um mapa vivo da região ${ }^{34}$.

Coube a esses estagiários, divididos em duplas com formações diferentes, percorrer os pontos de venda de alimentos e refeições do Morro Monte Serrat (açougues, padarias, restaurantes/ lanchonetes, mercados etc.) para identificar o acesso dos moradores aos mesmos. Do mesmo modo, os equipamentos sociais de outros setores, como Educação (escolas, creches), Cultura, organizações não governamentais, Esporte, lazer entre outros, foram mapeados. Esta etapa fundante de análise de fixos permitiu, por meio da compreensão dos movimentos humanos, ou seja, seus fluxos, o diagnóstico das necessidades dos grupos, famílias ou indivíduos ${ }^{35}$ que se tornariam alvo de ação conjunta na etapa seguinte.

O Monte Serrat é um ponto turístico de Santos, com 147 metros acima do nível do mar, em cujo topo encontram-se um mirante com vista panorâmica da cidade e o Santuário de Nossa Senhora de Monte Serrat, padroeira da cidade, construído em 1602. Os primeiros moradores chegaram à cidade de Santos no inicio da década de 196025 . Atualmente, ali vivem 300 famílias, conforme cadastro da equipe da USF; em torno de $75 \%$ dos moradores são oriundos de duas cidades do Estado do Ceará, Região do Nordeste brasileiro: distrito de Jamacaru em Missão Velha e Juazeiro do Norte.

A subida até o Morro pode ser feita por um bonde funicular, porém o acesso da maioria dos moradores se dá pela escadaria de 415 degraus $^{36}$. A população vive as mesmas dificuldades de inclusão que qualquer outra de baixa renda no espaço urbano: desemprego ou subemprego, alta densidade habitacional, difícil acesso 
ao lazer público, altos índices de violência ${ }^{25}$. A equipe da USF, assim como docentes e estudantes da Unifesp, tem acesso gratuito ao bonde funicular; entretanto, como a única parada é o topo do Morro, em razão de sua topografia, o funicular somente é usado para chegar àqueles domicílios próximos do mesmo.

A longa escadaria é o único acesso público aos residentes no histórico Morro Monte Serrat, sendo impossível a subida de carro, moto ou bicicleta, o que dificulta o transporte de mercadorias, como materiais de construção ou compras de supermercados. Antes de se circunscreverem a limites financeiros, as dificuldades de adquirir bens de consumo doméstico relacionavam-se à geografia do bairro. Inexistem mercados, drogarias, escolas ou outros equipamentos sociais no Morro Monte Serrat, registrando-se poucos bares e mini mercados com oferta limitada de produtos. Para utilizar tais serviços a população se desloca à região central circunvizinha. Os bens não chegavam lá em cima e aqueles adquiridos na cidade eram levados por carregadores, tornando-os mais caros.

A escadaria, as moradias encravadas na subida do Morro, as dificuldades de acesso e as diversidades que, inicialmente, traziam desconforto aos estudantes, foram minimizadas pelos contatos com as pessoas. Nessa trajetória, os obstáculos iniciais foram vencidos pelas descobertas no caminho, de modo que, aos poucos, o expressivo número de imigrantes despontava como interlocutores-chave para desvendar modos de cuidar da vida.

Entre incursões territoriais, encontros na escadaria, rodas de conversas, visitas domiciliares e reuniões de equipe, o mapa do território Morro/ Centro foi tomando vida. Um desenho cartográfico tridimensionalmente elaborado materializou-se sobre a cópia do mapa em papel. Esta foi uma ferramenta estratégica, construída em várias mãos, com todas as equipes de estagiários. Assim, cada retorno ao campo fazia emergir novos detalhamentos e outros registros apareciam e o princípio básico da atenção, que é a dimensão da escuta para identificar necessidades de saúde, foi se concretizando para os futuros profissionais de saúde em formação $0^{35,37}$.

\section{O diálogo Nutrição e Psicologia e as supervisões integradas de estágio}

A cada visita de reconhecimento do território intercalavam-se as supervisões integradas de estágio, para acompanhar e avaliar o processo e trazer à tona a riqueza daquela realidade. Paralelamente às supervisões ocorriam o planejamento conjunto dos estágios e as reuniões entre docentes e equipes da USF Monte Serrat.

Nas supervisões conjuntas de estágio, comum era o relato dos estudantes sobre a dificuldade de se fazer entender pelos trabalhadores da saúde, tendo em conta a maneira como estes conduziam a atenção aos casos e aos grupos e gerando tensionamentos por parte de alguns. Salientavam os mesmos a percepção de que o trabalho proposto não correspondia às expectativas das equipes que, na maior parte do tempo, esperavam uma reprodução mais linear do fazer específico de Nutrição e de Psicologia.

Segundo os estagiários, a discussão com os serviços sobre o trabalho em equipe interdisciplinar como estratégia para a integralidade, desembocava na definição de casos isolados para cada área específica de estágio, fragmentando o olhar sobre o usuário. Sobretudo os agentes de saúde guardavam a expectativa de tarefas exclusivas aos estagiários de Nutrição e de Psicologia, respectivamente. Sob este ponto de vista, encaminhavam-se casos de obesidade exclusivamente aos estagiários de Nutrição e casos de sofrimento psíquico aos de Psicologia, desconhecendo a interligação existente em boa parte desses casos. Frente a isso, os docentes supervisores dos estágios intervieram para encontrar as mediações que contemplassem tais demandas de forma integrada.

O embate entre uma formação centrada no paradigma das biociências e uma formação 
mais abrangente $5,6,39,40$ se fazia sentir nos depoimentos trazidos às supervisões, tanto pelos estagiários de Nutrição quanto pelos de Psicologia. Assim como as equipes dos serviços, os estudantes descobriam impasses e angústias oriundos de suas próprias expectativas sobre o fazer mais tradicionalmente conhecido de suas áreas de formação. A fragmentação do trabalho em saúde aparecia veladamente, quando "cada um queria dar seu ponto de vista sem discutir e levar em consideração a opinião dos demais".

Os estagiários relatavam a legítima preocupação "em fazer alguma coisa específica" de sua área de formação. Como era de esperar, por vezes oscilavam entre desejar o lugar tradicional de sua profissão e ir ao encontro de um trabalho em equipe $^{41-43}$, que perpassa competências específicas, mas que produz mais que a soma de profissões, dada a sua complexidade. Relativamente à formação em Nutrição, a expectativa era de que ao profissional nutricionista cabia prescrever dietas, a partir de anamnese e avaliação nutricional. Já os estagiários de Psicologia se viam na necessidade de trabalhar disciplinarmente questões referentes ao sofrimento psíquico das pessoas, como característica da ação do psicólogo.

A necessidade de integrar e ampliar conhecimentos, assim como de definir as especificidades do trabalho do profissional nutricionista, é objeto de reflexões. O compromisso com a formação de profissionais nutricionistas tecnicamente capazes, munidos de pensamento crítico e de engajamento com as questões sociais é ressaltado por diversos autores como condição essencial 2,6,11,12,44. Medeiros \& Diez-Garcia ${ }^{12}$ chamam atenção para a premência de convergir teoria e prática em ações resolutivas frente às demandas do real, sobretudo considerando o traço interdisciplinar e intersetorial que atravessa a problemática alimentar e nutricional contemporânea ${ }^{6,12}$.

Em análises sobre a formação, tem-se constatado um movimento constante de revisão de práticas e de inserção nos diversos contextos sociais brasileiros, para acolher as diferentes demandas frente à diversidade do País. Perante as desi- gualdades sociais vigentes, a Psicologia não pode se isentar do papel de promotora de intervenção planejada e de galgar uma prática que se afirme como transformadora ${ }^{4,14,45}$. Em pesquisa realizada por Rodrigues \& Badaró-Moreira ${ }^{45}$, percebeu-se que o acolhimento do sofrimento psíquico na Atenção Básica ainda tem ficado restrito aos Psicólogos, pois os demais profissionais incumbem o Psicólogo que atua neste nível de atenção o papel de tomar para si a escuta e a responsabilidade sobre todo usuários que demonstrem alguma sintomatologia referente ao sofrimento psíquico $^{45}$.

Frente aos desafios da formação, as demandas desses estagiários eram acolhidas e problematizadas nas reuniões de supervisão coletiva, partindo da escuta das vivências semanais e das análises dos Diários de Campo, sob a ótica das premissas do trabalho em saúde ${ }^{32,37,46}$. Nesse terreno salienta-se que o movimento em busca de novas configurações para o trabalho em saúde, a partir deste mesmo projeto pedagógico, foi descrito por outros estudos ${ }^{4,29}$.

O planejamento conjunto das ações decorria de um caminho já percorrido pelos professores responsáveis pelos projetos de estágio no território do Morro, que assumiram inserções no campo do ensino, da extensão e da pesquisa ${ }^{47}$. Isso potencializou a construção desta proposta conjunta de estágio, com forte compromisso com as necessidades de um território específico que requeria outros colaboradores que, aos poucos, foram se somando ao grupo.

\section{Das narrativas de histórias de vida aos Projetos Terapêuticos Singulares e seus desdobramentos}

A narrativa é reconhecida como potente ferramenta da pesquisa qualitativa, por facultar aproximação do universo de sujeitos e de grupos populacionais ${ }^{19,21-24}$. Com esse referencial, as visitas domiciliares revelavam a intimidade das famílias e apresentavam o cotidiano da vida naquele morro. 
Saudades que estavam escondidas dos familiares apareciam durante uma conversa familiar, à mesa da cozinha, conduzida pelos estagiários; lentamente, a aparente negativa das origens cearenses dava lugar a um sentimento de orgulho de sua cultura original. Ao longo do percurso, ouviu-se que a distância de alguns daqueles moradores do mundo citadino santista era real e o "abafamento das memórias do Nordeste" silenciava emoções.

Aos poucos as histórias de vida surgiam e aquelas pessoas se tornavam personagens de ricos e complexos relatos. Nesta etapa, o trabalho se desdobrou em um projeto de extensão conduzido pelas autoras do presente artigo: Terreiro lá de casa: tem pequi, cuxá, pão de queijo, jambu... tem congada, boi bumbá, maracatu.... Junto com os extensionistas (estudantes de Nutrição, Psicologia, Educação Física e Serviço Social) realizaram-se oficinas sobre identidade cultural e rodas de conversas com moradores, incluindo o estudo da cultura alimentar e das festas populares ${ }^{25,26}$. Eventos no topo do morro, envolvendo festejos e suas comidas típicas, se constituíram em importante espaço de convívio naquele território, estreitando os laços com a população e fortalecendo a proposta do Estágio Interdisciplinar de Nutrição e Psicologia.

No tocante à relação com a equipe do serviço, com o passar das trocas este trabalho favoreceu a escuta sensível, até então vista como princípio abstrato da política de humanização do SUS $^{31}$. A escuta ganhou organicidade, sendo incorporada como passo inicial de qualquer trabalhador da saúde; os Agentes Comunitários de Saúde (ACS), que já ouviam muitas histórias, passaram a dar maior importância ao que ouviam, ao compreender o significado daquela história na vida de quem a contava e seus efeitos no processo saúde/doença daqueles munícipes.

No aprofundamento dessa realidade os estudantes ouviam juntos as histórias, debatiam detalhes, compreendiam a complexidade de cada processo de adoecimento e, conjuntamente, também passaram a pensar em Projetos Terapêuticos
Singulares (PTS) a serem construídos com os munícipes e seus familiares. Passaram a entender, conforme depoimentos, que "hoje na área da saúde é mais do que você focar na doença". Aprenderam a acreditar que poderiam realizar atividades e "achar que deu errado, mas depois deu certo", exercitando o lidar com frustrações. Igualmente se confrontaram com suas questões pessoais como timidez, por exemplo, recorrendo ao apoio de sua equipe de trabalho, sem se sentirem menos capacitados por isto.

A partir da escuta, buscou-se criar vínculos com aqueles moradores, identificar suas necessidades, elaborar e desenvolver PTS durante o período de estágio. Neste sentido, a atenção nutricional, assim como a atenção psicossocial, figurou como momento peculiar de encontro entre os estudantes, os profissionais dos serviços e os usuários. O acompanhamento individual, o olhar para as singularidades, pretendia qualificar a atenção nutricional e a atenção psicossocial, pressupondo o resgate da autonomia, do autocuidado daqueles sujeitos, para a evolução favorável de seus processos, respeitando identidade cultural e condição socioeconômica e evitando a mera transmissão de orientações gerais de nutrição ou de psicologia ${ }^{9,47}$.

Construiu-se roteiro para aconselhamento nutricional, em trabalho processual de criação de vínculo com os sujeitos, para identificar histórias de vida, práticas alimentares, cultura alimentar e as demandas de saúde, e atuar sobre eles em parceria com os estagiários de Psicologia, as equipes e os próprios usuários. Simultaneamente, foi junto à equipe de ACS que os casos de sofrimento psíquico grave mobilizaram os estagiários de Psicologia naquele projeto comum. Iniciou-se longo processo de aproximação a estes casos, com visitas domiciliares e acompanhamento terapêutico, que demandaram o envolvimento das famílias.

Compunham também a rotina dos Estágios de Nutrição e Psicologia visitas domiciliares semanais com o médico de Saúde da Família, destinadas ao seguimento de usuários com dificuldade de locomoção, em sistema de rodízio (uma 
dupla de estudantes, sendo um de Nutrição e um de Psicologia). Nessa dinâmica ocorriam discussão prévia e posterior dos casos, juntamente com o médico, auxiliando a formulação de projetos terapêuticos e permitindo aos estudantes o aprendizado e o exercício da troca de saberes, requisito básico do trabalho interdisciplinar ${ }^{41,42}$.

Paralelamente, os estagiários de Nutrição realizavam uma monitoria informal do módulo Clínica Integrada: produção do cuidado, do eixo Trabalho em saúde. Esta consistia em apoiar os estudantes do $3^{\circ}$ ano dos diversos cursos com os casos que seriam acompanhados, de acordo com demandas da equipe da Unidade de Saúde da Família em que estagiavam.

Cumpre registrar que o envolvimento de projeto de extensão, assim como dos módulos curriculares do eixo Trabalho em saúde, perpassou a ideia central desta proposta de Estágio Interdisciplinar de Nutrição Social e Psicologia na Atenção Básica, a saber: a formação para o Trabalho e a Atenção Integral em Saúde, que tem nestes estágios curriculares o ápice de integralização desta formação (Figura 1).

No desenho fundante desta experiência de estágio interdisciplinar exposto na Figura 1, ressalta que a elaboração de PTS inicia-se no terceiro ano de graduação, no módulo teórico-prático Clínica Integrada: produção do cuidado (do qual uma das autoras deste relato é docente) e que conta com estudantes do $3^{\circ}$ ano de Nutrição, Psicologia e dos demais.

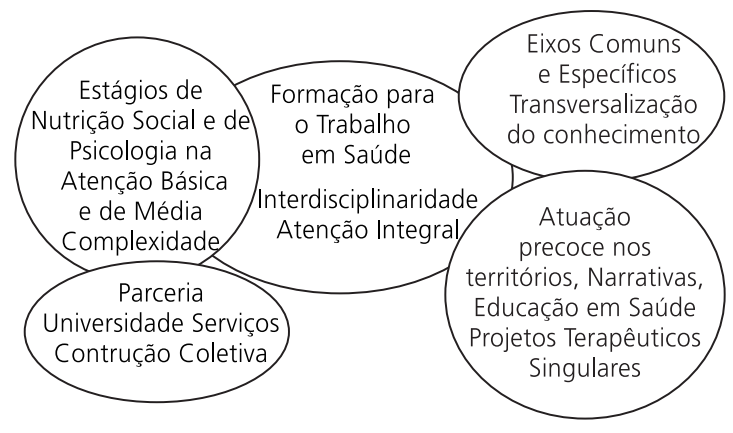

Figura 1. Estágios interdisciplinares de Nutrição Social e de Psicologia na Atenção Básica de Santos. Santos (SP), 2013
Segue-se o preceito da política de humanização envolvendo a clínica ampliada e compartilhada, as equipes de referência e o apoio matricial. Na perspectiva da clínica ampliada assume-se compromisso radical com o sujeito e também a responsabilidade sobre os usuários de cada serviço. Para promover uma clínica ampliada é preciso reconhecer os limites dos conhecimentos específicos, em busca da constituição de ações que incorporam a escuta, o vínculo, a afetação e o compromisso com a vida, que deve ser o objetivo de cada trabalhador da saúde. Um dos maiores desafios deste preceito é, portanto, a dificuldade de assumir e trabalhar em interdependência com outros profissionais e serviços, admitindo os limites de cada núcleo de conhecimento em busca de encontrar novos caminhos e soluções para além do saber e da competência de cada área ${ }^{32,37}$.

Ao serem concebidos em sistema de coresponsabilização, estes Projetos Terapêuticos Singulares, com metas e cronogramas definidos, se desdobraram em acompanhamentos domiciliares, além de atividades comunitárias de cunho educativo para a promoção de saúde. O trabalho em grupo compõe a Atenção Básica, respeitando necessidades dos usuários, entretanto não se pode acreditar que esta ação em si, se constitui como espaço inovador do trabalho em saúde, uma vez que a atuação no território deve levar em conta ações de educação em saúde e de troca de saberes, valorizando o repertório local 4,23,40.

No campo da formação em Nutrição, o planejamento e a execução das atividades educativas junto às equipes integra habilidades e competências profissionais. Entretanto, é preciso a seleção apropriada de estratégias de educação alimentar e nutricional, partindo da premissa de que a melhor dinâmica é aquela que resulte da interação entre equipe e usuários, respeitando e valorizando a troca de saberes, no lugar de palestras de sala de espera9,17,37.

Em análise da incorporação da educação alimentar e nutricional na política de alimentação e nutrição brasileira Amparo-Santos \& Santos ${ }^{39}$ constatou a persistência da lógica biomédica 
tradicional em detrimento do enfoque da promoção da saúde. A autora recomenda o fortalecimento da formação profissional nesse terreno utilizando "[...] alicerces científicos das práticas pedagógicas culturais que balizam a relação dos sujeitos e suas práticas alimentares" (p.461).

O diferencial desta experiência de Estágio Interdisciplinar de Nutrição e Psicologia foi a parceria consolidada entre serviço e universidade ao longo desse período, com a implicação direta da equipe de saúde da USF Monte Serrat (médico da família, enfermeira, chefe de seção, agentes de saúde, técnicos de enfermagem e dentista). Isso permitiu a continuidade e o aprofundamento de PTS pelos estagiários de Nutrição e Psicologia nos anos subsequentes, tecendo linhas de cuidado naquele território.

Assim têm sido acompanhados domiciliarmente portadores de doenças crônicas com dificuldade de locomoção, há alguns anos, em aconselhamento nutricional, psicossocial e fisioterapêutico, este último contando com inserções pontuais do módulo Clínica Integrada: produção do cuidado $\left(5^{\circ}\right.$ e $6^{\circ}$ semestres dos seis cursos de graduação). Este foi, seguramente, o resultado mais expressivo da trajetória iniciada em 2009, apontando para uma interface do trabalho desenvolvido com experiências destacadas de integração docente-assistencial que tiveram lugar em países com sistemas público de saúde, como Canadá, Cuba e Brasil, analisadas por Ellery et al. ${ }^{48}$.

Por outro lado, este estudo encerra limitações que não podem ser menosprezadas, considerando a ousadia da proposta de estágio interdisciplinar na formação de nutricionistas e psicólogos, que exige investimento significativo dos docentes envolvidos e dos serviços. Dúvidas e angústias foram geradas da parte dos estudantes, quanto ao processo ensino-aprendizagem, que se diferencia de modelos curriculares disciplinares, e aos óbices inerentes ao trabalho em equipe, que também mobilizam profissionais e pesquisadores do campo da saúde coletiva 29,30,42,43.

Outros limites se impuseram, entre eles a solução de continuidade das ações a cada troca de ciclo de estágio e questões estruturais do SUS santista, como a insuficiência de profissionais nutricionistas e de psicólogos no matriciamento à Estratégia Saúde da Família47.

\section{CONSIDERAÇÕES FINAIS}

Neste artigo analisou-se experiência viva de estágios interdisciplinares de Nutrição Social, de Psicologia na Atenção Básica e de Saúde Mental no território Morro-Centro em Santos, evidenciando ação conjunta que marcou uma trajetória de modos de conceber e realizar o trabalho em saúde.

Conclui-se que tal experiência potencializou o cuidado integral e contribuiu para qualificar a atenção neste território, ao fomentar as formas de escuta e cuidado, observando os sujeitos em seu contexto familiar e social e proporcionando maior compreensão do processo saúde/doença/cuidado. Ainda permitiu a horizontalização nas relações entre equipes de saúde e universidade, possibilitando discussões entre os diferentes cursos, promovendo atenção diferenciada aos usuários em estreita relação com os serviços.

Este modelo inovador de formação está repleto de desafios e por isso deve ser alvo de análises de seu cotidiano e de seus resultados. Como desdobramentos deste estudo, sugerem-se investigações longitudinais, utilizando metodologias quali-quantitativas, que favorecem o adensamento das formulações conceituais acerca da inserção de nutricionistas, psicólogos e demais profissionais da saúde, em movimento de articular pesquisa e intervenção, que marca o caráter da produção de conhecimento no campo da Saúde Coletiva.

Muitas disputas estão por ser vencidas em direção à capacitação de trabalhadores da saúde capazes de atuar na complexa problemática epidemiológica e nutricional contemporânea, que tem na epidemia de obesidade um de seus agravantes. Nesses termos, muito trabalho há por ser 
feito para integrar saberes, teoria e prática, competências técnicas e pensamento crítico em defesa do interesse público e da promoção da saúde no Brasil.

\section{A GRADECIMENTOS}

À Equipe da Unidade de Saúde da Família Monte Serrat da Sercretaria Municipal de Saúde de Santos (SP), pelo apoio e o protagonismo na realização desta experiência.

\section{COLABORADORES}

MAT MEDEIROS, FC BRAGA-CAMPOS e MIB MOREIRA participaram da concepção e do delineamento, da coleta de dados, da análise, da redação e da revisão crítica do manuscrito.

\section{REFERÊ NCIAS}

1. Amâncio Filho A. Dilemas e desafios da formação profissional em saúde. Interface. 2004; 8(15):375-80.

2. Recine $E$, Gomes RCF, Fagundes AA, Pinheiro ARO, Teixeira BA, Sousa JS, et al. A formação em saúde pública nos cursos de graduação de nutrição no Brasil. Rev Nutr. 2012; 25(1):21-33. doi: 10.1590/S1 415-52732012000100003

3. Mitre SM, Siqueira-Batista R, Girardi-de-Mendonça $J M$, Morais-Pinto NM, Meirelles CAB, Pinto-Porto $C$, et al. Metodologias ativas de ensino-aprendizagem na formação profissional em saúde: debates atuais. Ciên Saúde Colet. 2008; 13(Supl 2): 2133-44.

4. Roble OJ, Moreira MIB, Scagliusi FB. A educação física na saúde mental: construindo uma formação na perspectiva interdisciplinar. Interface. 2012; 16(41):567-78

5. Ceccim RB, Feuerwerker LCM. Mudança na graduação das profissões de saúde sob o eixo da integralidade. Ciênc Saúde Colet. 2004; 20(5):1400-10.

6. Medeiros MAT, Amparo-Santos L, Domene SMA. Education of dietitian's in Brazil: Minimum clock hours of instruction for a bachelor's degree in nutrition. Rev Nutr. 2013; 26(5):583-93. doi: 10.1590/S1415-52732013000500009

7. Nunes ED. História e paradigmas da Saúde Coletiva: registro de uma experiência de ensino. Ciênc Saúde Colet. 2011; 16(4):2239-43.
8. Chasin J. A Miséria Brasileira: 1964-1994 - do golpe militar à crise social. São Paulo: Estudos e Edições Ad Hominem; 2000.

9. Medeiros MAT. Desafios do campo da alimentação e nutrição na Atenção Básica. In: Garcia RWD, Cervato-Mancuso AM, editor. Mudanças alimentares e educação nutricional. Rio de Janeiro: Guanabara Koogan; 2011. p.173-80.

10. Soares NT, Aguiar AC. Diretrizes curriculares nacionais para os cursos de nutrição: avanços, lacunas, ambiguidades e perspectivas. Rev Nutr. 2010; 23(5):895-905. doi: 10.1590/S1415-52732010 000500019

11. Vasconcelos FAG, Batista Filho M. História do campo da alimentação e nutrição em saúde coletiva no Brasil. Ciênc Saúde Colet. 2011; 16(1):81-90.

12. Medeiros MAT, Diez-Garcia RW. Desafios para a capacitação no campo da alimentação e nutrição em saúde coletiva: notas preliminares. Demetra: Aliment Nutr Saúde. 2013; 11(8):349-54. doi: 10.12957/demetra.2013.5515

13. Prado SD, Bosi MLM, Carvalho MCVS, Gugelmin SA, Silva JK, Delmaschio KL. A pesquisa sobre alimentação no Brasil: sustentando a autonomia do campo Alimentação e Nutrição. Ciênc Saúde Colet. 2011; 16(1):107-19.

14. Dimenstein M. O psicólogo e o compromisso social no contexto da saúde coletiva. Psicol Estud. 2001; 6(2):57-63.

15. Brasil. Conselho Nacional de Educação. Resolução n 8, de 7 de maio de 2004. Institui as Diretrizes Curriculares Nacionais para os cursos de graduação em Psicologia. Brasilía: Conselho Nacional de Educação; 2004 [acesso 2014 out 4]. Diponível em: <http://portal.mec.gov.br/cne/arquivos/pdf/ rces08_04.pdf>.

16. Ceccim RB, Feuerwerker LCM. O quadrilátero da formação para a área da saúde: ensino, gestão, atenção e controle social. Physis. 2004; 14(1):41-65.

17. Santos LAS, Silva MCM, Santos JM, Assunção MP, Portel ML, Soares MD. Projeto pedagógico do programa de graduação em Nutrição da Escola de Nutrição da Universidade Federal da Bahia: uma proposta em construção. Rev Nutr. 2005; 18(1): 105-17. doi: 10.1590/S1415-52732005000100 010

18. Minayo MCS. A produção de conhecimentos na interface entre as ciências sociais e humanas e a saúde coletiva. Saúde Soc. 2013; 22(1):21-31.

19. Canesqui AM. Pesquisas qualitativas em nutrição e alimentação. Rev Nutr. 2009; 22(1):125-39. doi: 10.1590/S1415-52732009000100012 
20. Oliveira SG, Quintana AM, Budó M LD, Lüdtke MF, Casse PA, Garcia RP. Desafios nas entrevistas de uma investigação qualitativa: relato de experiência. Invest Educ Enferm. 2011; 29(3):485-91.

21. Lu AS, Baranowski T, Thompson D, Buday R. Story immersion of videogames for youth health promotion: A review of literature. Games Health J. 2012; 1(3):199-204. doi: 10.1089/g4h.2011.0012

22. Onocko Campos RT, Furtado JP. Narrativas: utilização na pesquisa qualitativa em saúde. Rev Saúde Pública. 2008; 42(6):1090-6.

23. Capozzolo AA, Imbrizi JM, Liberman F, Mendes R. Experiência, produção de conhecimento e formação em saúde. Interface. 2013; 17(45):357-70.

24. Silva DGV, Trentini M. Narrativas como técnica de pesquisa em enfermagem. Rev Latino-Am Enferm. 2002; 10(3):423-32.

25. Braga-Campos FC, Moreira MIB, Paula YA, Paulo LF, Medeiros MAT. O terreiro lá de casa: reconhecimento de bens culturais e bons encontros na comunidade. Rev Diálogos. 2010; 14:53-62.

26. Braga-Campos FC, Barbosa GT, Baldo RC. Breve ensaio sobre o convívio: de terreiros, de festas e de comunidades. Mal-Estar Subjetividade. 2012; 12(3-4): 703-24.

27. Cecilio LCO. As necessidades de saúde como conceito estruturante na luta pela integralidade e equidade na atenção em saúde: os sentidos da integralidade na atenção e no cuidado à saúde. Rio de Janeiro: Abrasco; 2001.

28. Universidade Federal de São Paulo. O Projeto Pedagógico do Campus Baixada Santista. Santos: Unifesp; 2006 [acesso 2012 fev 20]. p.128. Disponível em: <http://www.baixadasantista.unifesp.br/ projetopedagogico_baixada.pdf>.

29. Capozzolo AA, Imbrizi JM, Liberman F, Mendes R. Experiência, produção de conhecimento e formação em saúde. Interface. 17(45):357-70.

30. Imbrizi JM, Aguiar FBT, Fajardo A, Hirata JHB, Kawagoe K, Miyaura, et al. Condições de trabalho na estratégia de saúde da família: relato de experiência de extensão universitária com agentes comunitários de saúde. Cad Psicol Soc Trab. 2012; 15(1):153.

31. Brasil. Ministério da Saúde. Departamento de Atenção Básica. Política Nacional de Alimentação e Nutrição. Brasília: Ministério da Saúde; 2012 [acesso 2013 fev 10]. Disponível: <http://189.28.128.100/ nutricao/docs/geral/pnan2011.pdf>.

32. Brasil. Ministério da Saúde. Secretaria de Atenção à Saúde. Política Nacional de Humanização da Atenção e Gestão do SUS. Brasília: Ministério da Saúde;
2009 [acesso 2014 mar 15]. Disponível em: <http:// bvsms.saude.gov.br/bvs/publicacoes/clinica_ ampliada_compartilhada.pdf>.

33. Brasil. Ministério da Saúde. Secretaria de Atenção à Saúde. Departamento de Atenção Básica. Política Nacional de Saúde Mental. Brasília: Ministério da Saúde; 2002 [acesso 2014 maio 6]. Disponível em: <http://portalsaude.saude.gov.br/index.php/ cidadao/acoes-e-programas/conte-com-a-gente>.

34. Santos M. A natureza do espaço: técnica e tempo, razão e emoção. São Paulo: Edusp; 2006.

35. Cecilio L. Apontamentos teórico-conceituais sobre processos avaliativos considerando as múltiplas dimensões da gestão do cuidado em saúde. Interface. 2011; 15(37):589-99.

36. Novo Milênio Santos. Os bairros de Santos. 2012 [acesso 2014 mar 3]. Disponível em: <http://www. novomilenio.inf.br/santos/bairronm.htm>.

37. Demétrio F, Paiva JB, Fróes AAG, Freitas MCS, Santos LAS. A nutrição clínica ampliada e a humanização da relação nutricionista-paciente: contribuições para reflexão. Rev Nutr. 2011; 24(5):743-63. doi: 10.1590/S1415-52732011000500008

38. Campos GWS, Amaral MA. A clínica ampliada e compartilhada, a gestão democrática e redes de atenção como referenciais teórico-operacionais para a reforma do hospital. Ciênc Saúde Colet. 2007; 12(4):849-59.

39. Amparo-Santos LADS, Santos LAS. O fazer educação alimentar e nutricional: algumas contribuicoes para reflexao. Ciên Saúde Colet. 2012; 17(2):453.

40. Franco TB. Produção do cuidado e produção pedagógica: integração de cenários do sistema de saúde no Brasil. Interface. 2007; 11(23):427-38.

41. Campos GWS, Domitti AC. Apoio matricial e equipe de referência: uma metodologia para gestão do trabalho interdisciplinar em saúde. Cad Saúde Pública. 2007; 23(2):399-407.

42. Backes DS, Backes MTS, Erdmann AL, Büscher A, Marchiori MT, Koerich MS. Significado da atuação da equipe da Estratégia de Saúde da Família em uma comunidade socialmente vulnerável. Ciênc Saúde Colet. 2012; 17(5):1151-7.

43. Loch-Neckel G, Seemann G, Eidt HB, Rabuske MM, Crepaldi MA. Desafios para a ação interdisciplinar na atenção básica: implicações relativas à composição das equipes de saúde da família. Ciênc Saúde Colet. 2009; 14(1S):1463-72.

44. Vasconcelos FAG. A ciência da nutrição em trânsito: da nutrição e dietética à nutrigenômica. Rev Nutr. 2010; 23(6):935-45. doi: 10.1590/\$1415-5273 2010000600001 
45. Rodrigues ES, Moreira MIB. A interlocução da saúde mental com atenção básica no município de Vitoria/ ES. Saúde Soc. 2012; 21(3):599-611.

46. Garcia MAA, Ferreira FP, Ferronato FA. Experiências de humanização por estudantes de medicina. Trab Educ Saúde. 2012; 10(1):87-106.

47. Medeiros MAT, Martins PA, Braga-Campos FC, Laporte AS, Zangirolani LTO. A integralidade da atenção e as ações de nutrição na atenção básica de Santos. Relatório Final. Santos: Unifesp; 2014. p.1-124. Universal CNPq. Processo: $n^{\circ}$ 4860172011-7.

48. Ellery AEL, Bosi MLM, Loiola FA. Integração ensino, pesquisa e serviços em saúde: antecedentes, estratégias e iniciativas. Saúde Soc. 2013; 22(1):187-96.

Recebido em: 24/7/2014

Versão final em: 6/11/2014

Aprovado em: 12/11/2014 